\title{
The Influence of Crew's Psychological Factors on Ship Safety
}

\author{
Ang-Jun TANG ${ }^{1, a}$, Hong-Cang DONG ${ }^{2, b}$ and Wan-Zheng $\mathrm{Al}^{3, \mathrm{c}}$ \\ ${ }^{1}$ Marine College of Zhejiang Ocean University, Zhou Shan 316000, P. R. China \\ ${ }^{2}$ Marine College of Zhejiang Ocean University, Zhou Shan 316000, P. R. China \\ ${ }^{3}$ Marine College of Zhejiang Ocean University, Zhou Shan 316000, P. R. China \\ aEmail:2232941641@qq.com, ${ }^{\mathrm{b}}$ Email:dhcang@163.com, \\ 'Email:aiwanzheng@163.com
}

\begin{abstract}
Keywords: Psychological factors; ship safety; navigation education; psychological adjustment; psychological vent; decent work
\end{abstract}

\begin{abstract}
The mental health of seafarers has an important influence on the safety of ships. Eliminating and controlling the bad psychological factors of seafarers is of great significance to the safety of navigation. In order to reduce the occurrence of marine accidents, create a safe and harmonious nautical atmosphere and propose methods for controlling the psychological factors of the crew. Combining with the actual work, by analyzing the causes of the bad psychological factors of the crew and the important impact on the safety of the ship, the measures and suggestions for fostering the good psychological qualities of the crew are proposed. All walks of life should care for the crew, pay attention to the mental health of the crew, and pay attention to the safety of navigation.
\end{abstract}

\section{Introduction}

In recent years, the rapid development of the shipping industry, and the safety system composed of people, ships and the environment, the role of the people is still critical. In addition to the need for solid technology, seafarers in shipping also need to have a strong comprehensive ability, and the special nature of the ship's environment makes the psychological quality even more important. According to the statistics of the World Maritime Organization and the analysis of the causes of traffic accidents, human factors in the accident accounted for $75 \%$ to $80 \%$. If human factors together with the accidents caused by ships and the environment, then at least $90 \%$ of accidents are related to human factors [1]. Human factors not only include the seafarers' operational and operational capabilities, but also include psychological qualities. Among them, the seafarers' psychological quality is difficult to improve through a short period of unified management training. Therefore, only the continuous cultivation of seafarers' psychological quality can further reduce the occurrence of marine accidents. Ensure navigation safety.

\section{The Importance of the Psychological Factors of the Crew to the Safety of the Ship}

People's psychological state will have a direct impact on their working status and effect, and this law is particularly evident in the special work of shipping shipping. The well-being of the seafarers on the one hand makes it possible to normalize the knowledge and skills they already have; on the other hand, they can make up for the lack of knowledge and skills. A good psychological state can make people feel good, full of energy, quick thinking, can effectively improve work efficiency, and better handle various emergencies. The state of tension, anxiety, and depression will make people unresponsive, distracted and misjudged, which is very unfavorable for navigation safety. Only a good psychological quality is a reliable guarantee for the safe navigation of ships, so that sailing missions can be completed with high quality. Psychological factors are movements and changing psychological processes. They include people's feelings, perceptions, and emotions. They are often called "internal causes" of changes in the development of things. It restricts the exertion of other qualities and the improvement of work efficiency. At the same time it plays an 
integral role in other qualities. It is a guarantee for the seafarers' overall quality to be played and a key factor that affects the safety of ships.

\section{Good Seafarer Comprehensive Quality}

Seafarers' comprehensive qualities include five aspects: rich knowledge, skilled skills, good ideological and moral qualities, healthy physique, and good psychological quality. These five aspects are relatively independent and interrelated, interacting, and constraining.

\section{The Importance of Mental Status}

In the quality requirements of mariners, physical fitness is the prerequisite, professional and technical quality is the key, and psychological quality is the guarantee [2]. In November 2002, the Chinese H-Hatch encountered eight northwest winds after settling in three European ports after it was loaded and returned to Southeast Asia. 15 containers on board fell into the sea gradually under severe jolts, resulting in a relatively large economy. The loss was caused by the captain's chances of being lucky at the time, lack of comprehensive analysis, and insistence on safe operation. In April 2003, the two cargo ships collided in the fog along the coast of China because of the skipper's carelessness. They thought that the safety distance of 0.5 nautical miles was sufficient and eventually resulted in a collision. In April 2005, a miscellaneous cargo ship collided with a fishing vessel accident on the Chinese coast, which was also caused by three pairs of erroneous judgment on the dynamics of fishing vessels and adopting the wrong emergency avoidance measures. The above cases show that in emergency situations, seafarers often have some mistakes that do not occur in peacetime, and the importance of good psychological qualities to the safety of ships is evident.

The risks, arduousness, independence and variability of the seafaring profession will have a greater impact on the crew's psychology, and the seafarers need to bear more psychological pressure than other common professions, thus directly affecting the crew's mental health. However, because of the special nature of the navigation environment, it is required that the seafarers not only have a healthy psychology but also have better psychological qualities.

The research group composed of Huang Zhi and Zhai Yuanhe of Jimei University conducted a survey and analysis of the current crew and marine professional students (a total of 259 survey respondents, including senior seafarers and marine students) in 2008. The results showed that the crew the main psychological problems that arise are obsessive-compulsive symptoms, interpersonal relationships, depression, and paranoia, indicating that some of the seafarers in China have different degrees of psychological problems. The psychological survey conducted by the task force on 240 crew members in 2004 and interviews with some of the crew members also showed that some of the crew members' psychological problems were more serious than normal, and their mental health was lower than that of normal Chinese adults [3].

Prof. Zhang Jinpeng of Shanghai Shipbuilding University believes that human psychology affects people's potential and functions in various forms, and ultimately affects the realization of the entire group and organization goals. When people are in an unhealthy state of mind, such as nervousness, excitement, or loneliness, it is easy to cause an erroneous perception of external stimuli, or misjudgment, resulting in operational errors. In the three elements of navigational theory knowledge, practical skills and psychological quality, psychological quality plays a leading role and plays a decisive role. Because the mastery and use of theoretical knowledge and the correct use of practical skills are based on a certain level of psychological quality, leaving the psychological quality of this fundamental, it will affect the mastery and use of theoretical knowledge, serious operating skills will not be able to correct play, action aliasing [4].

\section{Measures and Suggestions for Training Psychological Quality}

Mental state is a characteristic of a person's mental activity during a certain period of time, such as distraction, fatigue, passion, calmness, tension, relaxation, etc. It has a tremendous impact on the safety of ship navigation. Some bad psychology, such as fluke mind, blind self-confidence and 
paralysis, barely victorious psychology, arrogant psychology, short-cut psychology, cowardly psychology, rebellious psychology, etc., can cause the parties to have no time to respond if sudden changes in the environment are encountered. ACCIDENT. In addition, such as the crew's pessimistic negative psychology, vanity, etc. will also make their judgment errors, take the wrong action [5]. To avoid the occurrence of these unfavorable factors, I believe that we can start from the following aspects.

\section{Strengthen Psychological Screening Test during School Education}

Psychological education and training in seafaring colleges and universities is the fundamental way to improve seafarers' overall quality and training qualified seafarers. Especially in current maritime education, psychological education and psychological self-adjustment courses should be introduced. At the time of enrollment, maritime schools may also introduce occupational propensity tests and psychological tests for the characteristics of navigational professions, select those who are willing to engage in seafarer careers and meet seafarers' psychological qualities, teach students in accordance with their aptitude, and fully expound their careers in the future. In the psychological problems that may be encountered, prevention and control, and enhance self-immunity.

\section{Good Team Management}

A good team can make people who work in it has a sense of belonging and pleasure and can improve work efficiency. On the contrary, living in a disputed group will lead to mental fatigue, which will lead to a variety of psychological problems. This requires the captain who is the leader and coordinator of the ship to use his authority and charisma to unite the entire crew, fully mobilize the enthusiasm of the crew, and coordinate relations between all parties so that each member can contribute and reflect value. And earn respect, so that members can trust and support each other, overcome difficulties and ensure the safety of navigation.

The captain must continuously improve his management level, keep pace with the times, and understand the character and characteristics of the old generation and the new generation of seafarers have targeted management, create a relaxed and pleasant working and living environment, and reduce the seaman's depression due to loneliness.

\section{Good Corporate Culture}

The shipping company or Crew Company should provide seafarers with more humane care, enrich the amateur life of the seafarers, improve crew working and living conditions, transmit more information in a timely manner, scientifically arrange seafarers' work and public holidays, and strengthen the concern for the seafarers' families. Help solve the practical difficulties of seafarer families. In addition, the company should also provide psychological assistance to seafarers, collect relevant information through psychological testing, follow-up feedback, and psychological counseling, establish seafarers' psychological records, and strengthen targeted training to guide them in learning various psychological adjustment methods to make them normal. The state of mind treats oneself, treats others kindly, spurs the motive that makes strenuous progress, and conducts specialized psychological counseling and guidance.

\section{Emphasize the Career of Seafarers and Ensure the "Decent Work" Of Seafarers}

Without the contributions of seafarers, half of the world's people will be frozen and the other half will be hungry. China is a large seaborne country and a large seafarer nation. It has 650,000 seafarers and is responsible for over $90 \%$ of foreign trade materials transportation. At present, China's seafarers are in the period of market transition, management reform and performance peak, the attributes of seafarers are changing, the functions of ship crew management are also changing, and service-oriented functions are becoming more prominent. There must be a seafarer public service system and a set of systematic legal and supervisory systems that are compatible with our seafarer's market, among which seafarer service systems are particularly urgent. For example, the establishment of a shipping authority and the seafarers' association is not intended to be profitable. Seafarers club. 
The ship company and ship leaders must effectively arrange personnel on duty and rest time in accordance with the requirements of the "STCW Convention" and the "International Convention on Maritime Labour." Reasonably arrange exercises such as drill training, cleaning of cargo compartments, cargo lashings, etc. to ensure that the crew members receive adequate rest, prevent the body and mind from reacting due to fatigue and lead to the weakening of judgment ability, as well as prevent pressure caused by fatigue and cause psychological problems.

\section{Strengthen Self-Paced Ability Training}

Blacksmith need its own hardware. Anything that wants to survive must adapt to the environment. When we are faced with environmental pressures, we must adopt various forms to timely adjust our mentality, cope with stress, and make ourselves better able to adapt to the environment.

First of all, we must recognize the difference between land life and sea life. Second, we must strengthen the adaptability of interpersonal relationships. To get along well with people and live in harmony, we must not only change the perspective of looking at problems, but also learn to empathize. Third, we must Pressure has some understanding and preparation; Fourth, we must also learn some methods to eliminate negative emotions, such as the transfer of emotions, proper venting, reading more, listening to more music, and developing a sense of humor.

\section{Optimizing the Marine Environment}

According to research by psychologists, human visual, auditory, taste, and tactile factors all have a certain influence on human psychology. In other words, the materials and colors of ships in shipping will affect people's perception and mental state. Therefore, when designing ships, we must fully consider the particularity of shipping and the psychological needs of seafarers in the environment, and create a good work and rest atmosphere for the crew. It is necessary to fully grasp the shape, color and space of the machine and minimize the noise of the machine so as to facilitate the use of the machine by the crew while reducing the unnecessary physical and psychological losses of the ocean-going crew, improving the working efficiency and satisfying the comfort and health of the crew. The request.

\section{The Role of the Captain}

The captain is the soul of the ship and leads all the crew to work together to reach the other side. The captain should have the courage to fear and change without fear, and command the overall situation, command the determined mind, and master the virtues of good-neighborliness, hardness and softness. He must be able to establish a good prestige and manage the ship well. Create a good working atmosphere and relieve the pressure caused by the work environment.

\section{Walk into Seafarers to Learn About Seafarers}

Seafarers have a special working environment. They are far away from land and far away from their homes. They are a lonely and closed world, and they are psychologically more or less psychologically abnormal. The modernization of ships has greatly reduced the number of seafarers in each ship. The normal on-duty arrangements make contact between crew members and communication with the outside world very scarce. The noise and bad weather caused by the operation of the ship for a long time will cause the seafarers to feel anxious psychologically, which will greatly affect the physical and mental health. It is necessary for the captain to understand the individual characteristics of each crew member, and he can also learn from his partners about the situation. They approached the crew and contacted them more. They shared every meal with the seafarers and brothers.

\section{Master the Necessary Physical and Psychological Knowledge}

From the point of view of managing the ship's leaders, the captain should understand the behavioral sciences and physical and mental health knowledge of some people, understand the changes in people's emotions in special circumstances, and learn and study how to guide and resolve the working methods of seafarers' physiology and mental disorders. 
Three rounds of the BSS round were a very cheerful guy, but after berthing at SH Port, he suddenly said nothing and was worried. The captain learned from his good partner that his wife was hospitalized because of illness and that the family was missing. Because the ship is about to sail immediately, the captain first contacted the company personnel and the union, and the union sent personnel to take care of it. The captain asked the company to use a dispatching system to inform the ship if the maritime communication was difficult. One week later, her family's condition improved and he was discharged from the hospital. The three teams were completely relieved and worked at ease.

In many cases, psychological communication and evacuation are necessary, especially when the crew members suffer from illness. When they do not understand the condition, due to the lack of medical conditions, anxiety and fear multiply; the captain should use his knowledge and shore-based support to judge the condition of the patient. Development, and can be encouraged by the shore-based doctors, at the same time inform their medical status, the state of the ship, to support its victory over the pain.

\section{Conclusion}

Ship safety accidents have brought great harm to people's economic and personal safety. The crew is the manipulator and the manager of the ship. To ensure the safety of the ship and prevent and reduce the occurrence of maritime safety accidents, the key lies in the crew of the first line. The psychological quality of the crew also involves many factors. It is particularly urgent to discuss the influence of the psychological factors of the crew on shipping safety and improve the mental health of seafarers. This is not only the need for the sustainable development of the shipping industry, but also the need for China to move from a seaborne power to a maritime power.

\section{References}

[1] Wang Zuo, Qiao Zhebin, Li Xin, et al. Analysis of crew quality and maritime traffic safety [M]//Comprehensive Quality and Safety of Crew. 2005.

[2] Yao Yonghui, Li Qihua. The influence of the psychological quality of mariners on the safe navigation of ships and the countermeasures [C].

[3] Huang Zhi, Yan Yuanhe, Zhang Hao. A preliminary analysis of the seafarer's psychological problems and psychological quality evaluation standards [J]. Maritime Education Research, 2009(3):9-12.

[4] Zhang Jinpeng. Analysis of human factors in marine traffic accidents [J]. Journal of Shanghai Ocean Shipping University, 1998(1):35-40.

[5] Shi Chunlin, Yu Xia. A very unique and practical book of psychology - Reading "Navigation Psychology"[J]. World Shipping, 2011(6):55-56. 